\title{
Improving the Work Breakdown Structure of the Plant Installation - Case: Asphalt Plant
}

\author{
S. ABUJUDEH \\ University of Debrecen, Faculty of Engineering, Engineering Management (MSc), saidabujudeh@gmail.com
}

Abstract. The improvement of the project management forced the industrial organizations to focus on using the project management techniques in their industry, to plan and control the workflow to achieve their targets, further to increase the satisfaction of their customers. One of the most common project management tools are used is the work breakdown structure (WBS), which provide a framework for the implementation of the project scope including project planning, scheduling, monitoring, control, and estimation. Depending on the top-down approach the project activities will be broken into smaller parts that can be measured and controlled during the project implementation. The well-defined construction of the structure contributes to making the project more realistic and visual. However, the misunderstanding of the project WBS among the project team creates deflection and misinterpretation of the project scope. The main issue of this research is to improve the WBS of the installation plan and develop a standard WBS for plant installation. The research was limited to Asphalt plant installation WBS as a case study to identify the weaknesses of the current WBS at the case company which leads to extra installation time and cost. The research is offering a template WBS based on the company logic, defining the frequent risks that affect the plant installation based on the WBS and suggesting a suitable response strategy by recommending a control framework to monitor and control the WBS schedule throughout all installation phases.

\section{Introduction}

The complex activities of the modern industry, due to the huge technological revolution and the changes in the business environment, forces the scientific and researchers to develop the field of projects management to coordinate, control and simplify the complexity of the modern industry, Nowadays, the projects management profession covered almost all life aspects, given that the concept of the management, in general, is suited for all human activities and the daily routines. Each of this activity can be considered as a project, which has a unique and temporary nature, limited by a specific timeframe and budget, also, varies from small to a complex project. Achieving the project objectives requires high project management knowledge and skills [1]. Therefore, the need to improve the projects management tools and techniques become very important, by meeting the project targets and delivering the project output at a certain level of quality.

The plant installation project is similar to other projects. in order to be performed, the work tasks need to be divided into smaller tasks. Based on the top-down approach by splitting the components of the project into a sub-component or sub-deliverables work that can be executed and managed and controlled within the project lifecycle, structuring the project components in sequenced graphical form, such approached is called the project work breakdown structure [2, 3]. Many factors affect the 
plant installation. In such cases, may lead to project failure or overrun project constraints such as; the project scope, schedule, cost, and quality. Project constraints are specific conditions which should be met, and have a high impact on customer satisfaction [4] Thus, the better project planning and control usually increase the project success.

This research aims to examine the WBS of asphalt plant installation as a case study, to measure the weakness of the current installation WBS, and to evaluate the installation risk affected on the plant installation. In addition to proposing suitable WBS that can improve the plant installation at the case company. As well as, to establish a framework to control and monitor the WBS implementation.

\section{Work Breakdown Structure}

According to the PMBOK guide, the work breakdown structure is "A hierarchical decomposition of the total scope of work" [5]. The project works can be executed by the project members to attain the project targets and generate the requested outputs. By considering the complexity of the project, the decomposition level will vary to cover all project phases and give clear and detailed information about the project scope to fit with project objectives. The WBS helps the project manager to establish full project management framework which controls all project activity [6].

The WBS is used for formalizing the project scope. organizing the schedule and estimating the project cost as well as allocating the activities responsibility and resources. [7]. Devi and Reddy reported that WBS is the fundamental step in project planning, cost estimation, scheduling and resource allocation [8]. Furthermore, the previous project WBS act as a template for developing the new project WBS which reducing the total time of project planning. [9]

The Project management institute clarifies that the main purpose of the WBS as a project planning tool is to organize the project scope [10]. Therefore, the well-defined creation of the structure contributes to making the project more realistic and visual. Fleming and Koppleman stated that "The WBS provided an opportunity for all key functions on a project to view the project in the same manner, to speak a common project language for the first time" [2]. One of the main factors of increasing the project success is the appropriate use of WBS [11].

The WBS is a common approach in project management, but sometimes there are some misconceptions in performing it. The lack of awareness of WBS importance among the project members during the project execution leads to deflection and misinterpretation for the project scope. [12]. Thus, the development of good WBS will let the project team achieve the target of project scope, time and cost $[6,8]$. The benefits of appropriate WBS appears in several locations before, during and after the project [13]. Such as; defining the project scope that should be implemented to meet with the project objective. reducing the project complexity by the decomposing process, resources allocation effective tool, simplify the project risk recognition which can be immediately treated, and the accurate estimation of the project cost and time.

The WBS should be developed to ensure the maximum interpretation of the project scope [14]. The WBS should include $100 \%$ of the work defined in the project scope and should cover all deliverables, in terms of work, need to complete the work package. This rule is defined as $100 \%$ rule and it is the 
most important principle should be considered during the creation of the project WBS. According to Haugan "The next level decomposition of a WBS element (child level) is 100 percent of the work applicable to the next higher (parent level)" [6]. Thus, the sum of the total work at the lowest levels should be enough to perform the higher levels and no need to perform extra work and no work should be missed. However, the level of details in the WBS varies according to the size and the complexity of the project. the WBS levels can be increased to reach the low level which is the work package of the WBS that required to accomplish the project.

The work package is the work activities represent the last level of the WBS for which duration, cost, and resources can be estimated and controlled and the work can be scheduled and monitored. [5] Usually, the amount of control required to manage the project determines the level of details. Gary Heerkens presents a $4 \%$ rule for decomposing [13]. Based on this rule, the WBS elements can be broken down to reach the level where the last element of the WBS elements forms $4 \%$ of the total work of the project, for instance; for 100 days scheduled project, the level of the last element should be equal to 4 days.

There are several preparation methods can be used to create a WBS, the most common methods used to create a WBS include a top-down approach, and bottom-up approach [10]. In the top-down approach the project final products will be identified to determine the major deliverables or subcomponents, then the major deliverable or sub-components will be broken down to a level of detail suitable for effective management and control. While in the bottom-up approach all work packages or deliverables involved in the project will be identified and linked logically together to represent the deliverables or sub-components in the upper level, this process will be repeated until reaching the final project product or service.

The project WBS can be structured in many forms or structures according to the organization culture, stakeholder impact and project complexity. One or combination of several forms can be used based on the project requirements such as system form, product components form, and function form [10], In the system form WBS, the project is broken down into several systems where the project was undertaken to accomplish these systems, meanwhile in components form WBS, the project is itemized into different components and the WBS is structured accordingly. And so is the case in the functional WBS form, the WBS is created according to an organizational or functional unit of the project such as engineering, manufacturing, and management or to functional process, Such like an erection, testing, and commissioning.

\section{Case study: Asphalt Plant Installation WBS}

\section{Problem identification}

The research intentions to improve the installation WBS at the case company by examining three models of asphalt plant produced by the company, in order to identify; 1) the current installation WBS and determine the weaknesses lead to the poor implementation of the installation WBS. 2) the opportunity that can drive to increase the efficiency of the installation WBS. 
The action research method was used to analyze the current installation WBS, Therefore the historical data from the installation team was necessary to evaluate the real situation of the WBS. As well as, the suggestions from the company engineers and workers. Based on the knowledge and experiences of the installation team, the information was gathered and analyzed to find the best installation WBS and to identify the main risks affected on the installation phase. Accordingly, the plant installation process sequence can be illustrated as per shown in figure 1 .

The data from the company's information system showed that the plant installation constitutes one phase of the total asphalt plant manufacturing process. All production processes are integrated and managed through Systems, Applications, and Products (SAP) software and using a master WBS. In addition, due to the nature of the company products, the installation phase always takes place at the customer location under deferent weather condition. this fact makes the control of the installation phases so hard. At the company, the project and service department is responsible for the plant installation.

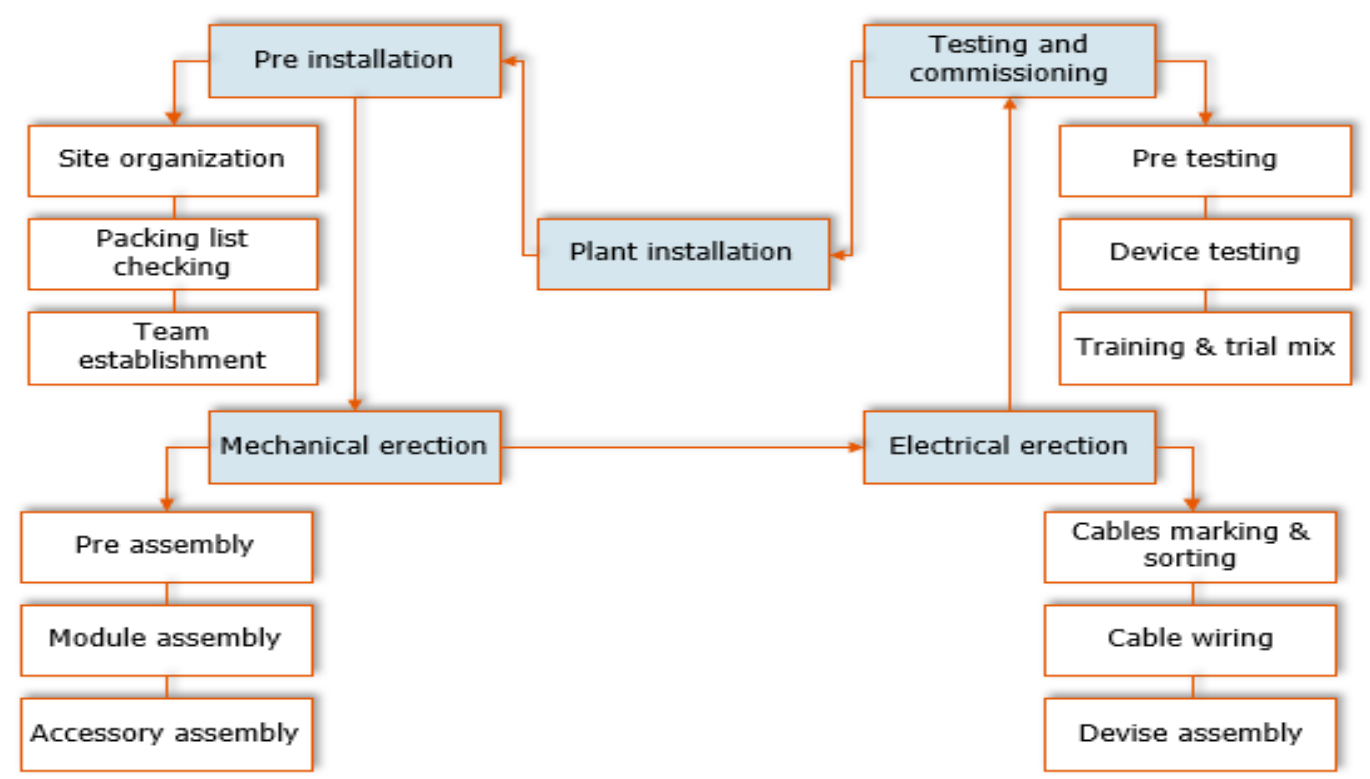

Figure 1: Asphalt plant installation process map [15]

The company reports showed that many working hours had been lost due to several internal and external factors. The variation among similar asphalt plant models makes the need to create a standard WBS installation very important to avoid the additional cost and effort during the plant installation process. Table 1 shows the summary of installation reports for three models of asphalt plants, based on its size, where the source of delay combined under three main headings, internal by the company, external by the customer, and due to weather condition.

\begin{tabular}{|l|c|c|c|c|c|c|}
\hline \multirow{2}{*}{ Plant model } & \multicolumn{2}{|c|}{ Work } & \multicolumn{4}{c|}{ Lost Hours } \\
\cline { 2 - 7 } & Days & Hours & Company & Customer & Weather & \% Value \\
\hline Model I & 75 & 620 & 40 & $\mathbf{7 5}$ & 8 & $19.83 \%$ \\
\hline Model II & 60 & 485 & 24 & 50 & 10 & $17.31 \%$ \\
\hline Model III & 40 & 320 & $\mathbf{6 7}$ & 30 & 0 & $30.31 \%$ \\
\hline
\end{tabular}

Table 1. Installation report summary [15] 


\section{Problem analysis}

By considering the number of installations every year; the problem becomes clearer. In general, each model of the asphalt plant has a unique nature, due to the different customer requirement, as well as, the complexity for each model varies in size. Therefore, to determine the sources of the problem, it is important to study each model and try to find the reasons for the variation of the installation period. By solving this issue, the company can reduce the cost and time, as well as, increase customer satisfaction. Table 2 reviews the time and cost estimation based on the current installation WBS.

\begin{tabular}{|l|c|c|c|}
\hline Plant model & $\begin{array}{c}\text { Estimated working } \\
\text { Days }\end{array}$ & $\begin{array}{c}\text { Estimated working } \\
8 \mathrm{H} / \mathrm{D}\end{array}$ & $\begin{array}{c}\text { Estimated installation } \\
\text { cost }\end{array}$ \\
\hline Model I & 75 & 600 & $€ 30,000$ \\
\hline Model II & 50 & 400 & $€ 20,000$ \\
\hline Model III & 30 & 240 & $€ 12,000$ \\
\hline
\end{tabular}

Table 2. Installation WBS time and cost estimation [15]

The last ten installations process collected for each targeted model, by calculating the average working days after eliminating the lost days. Although the data shows that the average installation time is similar to the estimated time, the total installation time shows that many working days were lost. Table 3 summarizes the analysis result.

\begin{tabular}{|l|c|c|c|c|c|}
\hline \multirow{2}{*}{ Plant model } & \multirow{2}{*}{ Average work / day } & \multicolumn{3}{|c|}{ Average lost / day } & Overall \\
\cline { 3 - 5 } & & Company & Customer & weather & average \\
\hline Model I & 75 & 7 & 5 & 4 & 91 \\
\hline Model II & 50 & 6 & 5 & 3 & 64 \\
\hline Model III & 30 & 6 & 4 & 2 & 42 \\
\hline
\end{tabular}

Table 3. Overall average installation time [15]

It's clear that the internal and external factors have a high impact on the installation time, this fact creates extra efforts and cost. The company service engineer normally is responsible for implementing the installation WBS, meanwhile, the customer is responsible for preparing the installation job site, also, to provide all labor and machinery. Both the service engineer and the customer team form the installation team. The qualitative research methodology was coeducated to clarify the root cause of the extra time and cost and to identify the frequent risk during the installation phase [16]. The service engineer is the most important source of information and experience to develop clear WBS. The company experts' engineers and project manager were asked about their opinions about the problem causes and their opinions ware as follow:

- The customer role is not considered during the development of the installation WBS.

- The role of the service engineer and his impact on the work schedule.

- The weak risk assessment strategy that delays the risk response.

- Unclear WBS due to confusion with the master WBS of the asphalt plant manufacturing.

- The missing framework to control overall WBS work packages.

According to experts' opinions, the company should improve customer participation in creating the installation WBS, considering that they are responsible for a large number of days lost. As well, the 
project manager should recognize the role of the service engineer and improve his managerial skills, given that he is the installation team leaders. At the last step, the project manager should create installation WBS separated from master WBS to include all internal and external factors that affect plant installation. Furthermore, it is necessary to develop a control framework to control the WBS implementation and enhance the risk assessment strategy.

\section{Installation risk assessment}

The risk assessment survey was conducted during the research to categorize the frequent risk. The company reported all risk at three categories based on the risk source. This assessment strategy was acknowledged by PMI [5]. Figure 2 presents the risk breakdown structure (RBS). The RBS was developed according to company experts and previous project reports. There are several risk variables based on risk sources, for instance; the company participates in the total risk under the work package heading by missing schedule activity or poor work volume estimation which indicates to the poor WBS, Also, the customer is responsible for delaying the works by uncompleted ground works at the pre-installation phase or lack of expert technician during the installation.

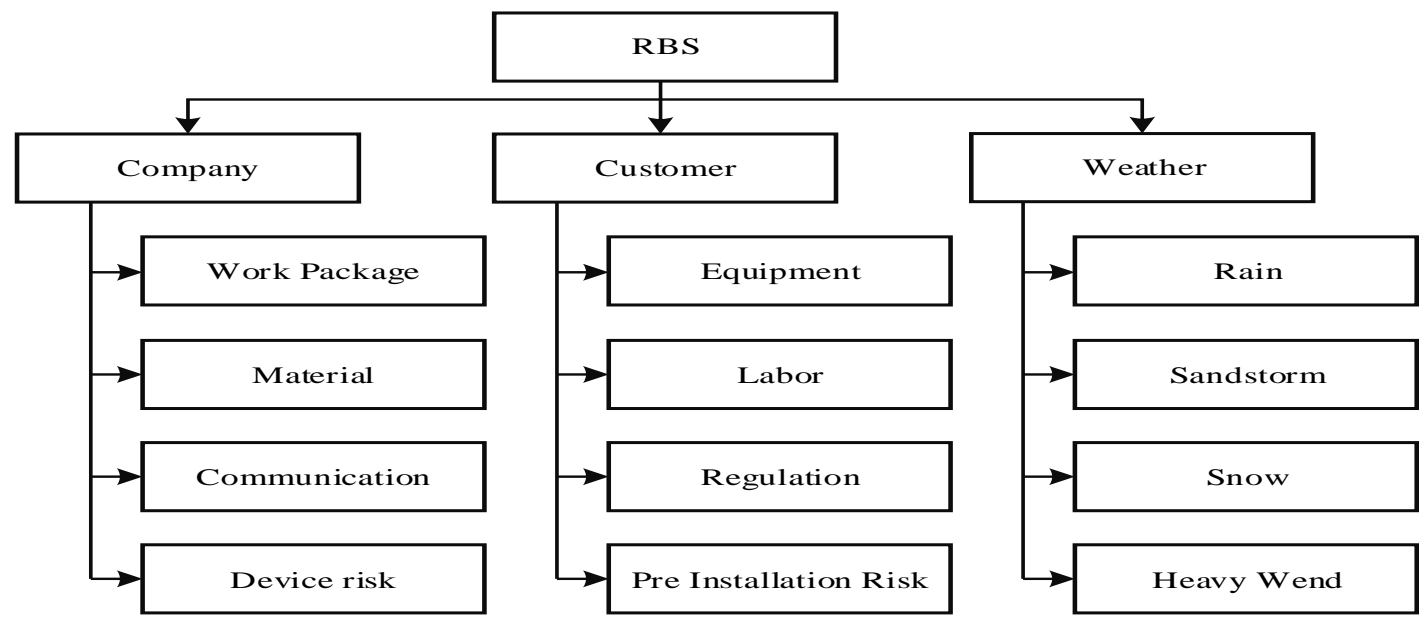

Figure 2. Installation RBS [15]

The installation environment or weathers has significant impacts on the installation process, which also need a suitable treatment in the planning process to minimize the effects of the weather risk, such as modifying the schedule or the installation date. However, according to the RBS, 20 risk variables were identified including the work activities, resources, and all possible source of risk [17]. A scale of five points was selected to obtain the probability of the risk events (P). In addition, a scale of five points was selected to find the impact of the risk factors (I). Once the probabilities and impacts are determined, the score $(\mathrm{S})$ can be calculated with the following expression [1].

$$
S=P \times I
$$

The probability and impact matrix or risk level matrix illustrates a risk rating assignment for each risk event [18]. Table 4 shows the combination of impact and probability where the cell color reparents the risks priority as follow: 
- High priority risk: a critical risk that has a significant impact on the work performance and requires immediate treatment, is marked with red. Score $>10$.

- Moderate risk: is a special event may affect the work performance, is marked with yellow, and can be treated directly by the related party, $6>$ Score $\leq 10$

- Low Risk: the risks that are marked with blue have a little effect on work performance and can be managed directly by the service engineer, Score $\leq 6$.

\begin{tabular}{|c|c|c|c|c|c|c|c|}
\hline \multirow{3}{*}{\multicolumn{3}{|c|}{$\begin{array}{c}\text { Risk Evaluation Matrix } \\
\text { Score = Impact X probability }\end{array}$}} & \multicolumn{5}{|c|}{ Risk impact } \\
\hline & & & \multirow{2}{*}{$\frac{\text { very low }}{1}$} & \multirow{2}{*}{$\frac{\text { low }}{2}$} & \multirow{2}{*}{$\frac{\text { moderate }}{3}$} & \multirow{2}{*}{$\frac{\text { high }}{4}$} & \multirow{2}{*}{$\frac{\text { Very high }}{5}$} \\
\hline & & & & & & & \\
\hline \multirow{5}{*}{$\begin{array}{l}\vec{D} \\
=0 \\
0 \\
0 \\
0 \\
0 \\
0\end{array}$} & Very frequent & 5 & 5 & 10 & 15 & 20 & 25 \\
\hline & Frequent & 4 & 4 & 8 & 12 & 16 & 20 \\
\hline & Fairly frequent & 3 & 3 & 6 & 9 & 12 & 15 \\
\hline & Accidental & 2 & 2 & 4 & 6 & 8 & 10 \\
\hline & Rare & 1 & 1 & 2 & 3 & 4 & 5 \\
\hline
\end{tabular}

Table 4. Risk assessment matrix [modified 18]

The data were gathered using a survey questionnaire. The target respondents in this research were the company experts, who had experience in the installation of the asphalt plant A total of 20 surveys were shared with company staff and their freelancer's, of which 16 responses were received back with a rate of $80 \%$ response. the survey participants represent different locations and responsibilities as well as different experiences level. Table 5 shows the respondent profile.

\begin{tabular}{|l|l|c|l|l|l|}
\hline \multicolumn{2}{|c|}{ Position } & \multicolumn{2}{c|}{ Experience } & \multicolumn{2}{c|}{ Education } \\
\hline Project Manager & 3 & $\leq 5$ & 4 & High school & 4 \\
\hline Service Engineer & 9 & $5-10$ & 5 & Bachelor degree & 11 \\
\hline Staff & 4 & $>10$ & 7 & Master degree & 1 \\
\hline Total & \multicolumn{5}{c|}{16} \\
\hline
\end{tabular}

Table 5. The respondent profile [15]

The result of identifying the risk variables categorized in groups as shown in table 6.

\begin{tabular}{|l|l|l|l|}
\hline ID & Risk events & Score & Category \\
\hline R9 & Missed parts (time to receive it) & 13.43 & Material \\
\hline R17 & Lack of specialized labor / Lack of qualified labor & 12.75 & labor \\
\hline R16 & Low Labor productivity & 12.62 & labor \\
\hline R6 & Manufacturing mistakes (repair and modification) & 12.08 & Activity \\
\hline R10 & Defective parts (need replacement) & 11.51 & Material \\
\hline R14 & Poor equipment scheduling (availability) & 10.76 & Equipment \\
\hline R7 & Completion of pre-installation work (such as foundation) & 10.65 & Activity \\
\hline R3 & interdependence of plant installation activities & 10.45 & Work packages \\
\hline R20 & Weather conditions associated with plant installation location & 9.84 & Weather \\
\hline R11 & Unconformity parts (need modification) & 9.03 & Material \\
\hline R13 & Equipment breakdown and time require repair or to replace & 8.77 & Equipment \\
\hline R18 & Shortage of labor due to labor accident or absent & 8.63 & Labor \\
\hline
\end{tabular}




\begin{tabular}{|l|l|l|l|} 
R15 & Equipment not suited for installation & 7.95 & Equipment \\
\hline R12 & time to transfer plant material to the task location & 6.87 & Material \\
\hline R1 & Unscheduled work (optional parts) & 6.75 & Work packages \\
\hline R19 & Language barrier among workers/supervisors & 6.23 & Labor \\
\hline R2 & lack in estimating the volume of work & 5.96 & Work packages \\
\hline R5 & Installation faults (rework) & 5.48 & Activity \\
\hline R4 & work breakdown structure level of details is not enough & 5.34 & Work packages \\
\hline R8 & Missing manuals & 5.12 & Material \\
\hline
\end{tabular}

Table 6. Risk variables score [ modified 17]

The survey result shows that there are eight risks with high priority, the experts put the missed parts risk variable $\mathrm{R} 9$ on the top of the list, as well as, defective parts R10 which are both categorized under material category and that represents the impact of the material status on the installation process. Manufacturing mistakes R6 under the activity category, and interdependence of plant installation activities R3 under the work packages category, which altogether forms the first half of the high priority risk. Unfortunately, the source of the for risks are the company, therefore, immediate action should be taken to solve or reduce these kinds of risk. However. all of these risks are varied among the plant installation process, that makes the correction action so hard.

In addition, the result shows that the customer is the sources of the second half of the high priority risk. Lack of specialized labor - Lack of qualified labor R17 and Low labor productivity R16, both risks are associated with the labor category which is mainly supplied by the customer, the other two risks caused by the customer are the poor equipment scheduling or availability R14, and completion of preinstallation work R7 such as the underground works, these risks are respectively associated with equipment and activity categories. Therefore, the risk response must be clear for both parties, the company, and the customer should work together to manage these risks that appear during the installation process. The experts confirmed that the labor and equipment risk, in many cases, lengthen the installation process. Thus, a good equipment plan, as well as sufficient resources allocation, easily lead to solving the impact of these risk.

The result shows eight risk variables with moderate priority, these risk variables managed by the plant installation team, such as the weather conditions associated with plant location R20, the right response for this risk is very important. this risk variable will be assessed by the service engineer with the help of the customer. As well as, the unconformity parts R11, they should modify it and report to the project manager the sources of this risk whether it was due to the material or the product design, and so is the customer is responsible for providing the installation equipment to avoid the risk of the low equipment quality that leads to equipment breakdown and increases the time required to repair or to replace it, R13 and R15. Also, the risk related to labor quality such as; R18 and R19, require a cooperation among the project organization to recover any impact caused by the labor quality.

The risk variables, the time to transfer plant material to the task location R12 and the unscheduled work R1, according to the experts, are located at the second priority, but at the same time can be considered as a result of poor installation WBS, given that it is possible to organize the site layout to reduce the time to transfer the material at the job site. Also, to clarify the unscheduled work related to 
the optional parts to avoid any extra time need to erect any optional parts. As in the high priority risk, each party is responsible for $50 \%$ of the moderate priority risk.

Four risk variables were rated with low priority by the company's experts; R2, R5, R4, and R8. According to their experience, experts confirmed that they could accept this type of risk variable, and they could cover the resulting impact.

Briefly, it is clear that the company and the customer are participating almost with the same percentage in the risk, this means that increasing the cooperation between both of them can improve the installation environment. Therefore, improving the installation WBS will help both parties to reduce the total cost and time required for the plant installation.

\section{Proposed Installation WBS}

The proposed WBS in this research designed according to the problem interpretation of the plant installation. The proposed installation WBS will attempt to treat the WBS weaknesses as well as, its' implementation and try to reduce the installation period and cost. As a result of the analysis, the company and their customer's effect on the problem became very clear. Therefore, it is logically clear that there are three main participants have had a high impact during the installation process, mainly; the company project manager, the service engineer - who is the installation team leader - and the customer.

The proposed WBS developed based on three factors as follows:

- Increasing customer participation in creating plant installation WBS.

- Improving the role of the service engineer who is responsible for WBS implementation.

- Improving risk management techniques by establishing a framework to control the WBS implementation.

However, the project management techniques remain the key to successful plant installation by creating a standard WBS for the plant installation. The dynamic environment of the plant installation was considered by the proposed WBS, to make the WBS more fixable and valid for several types of an asphalt plant. 


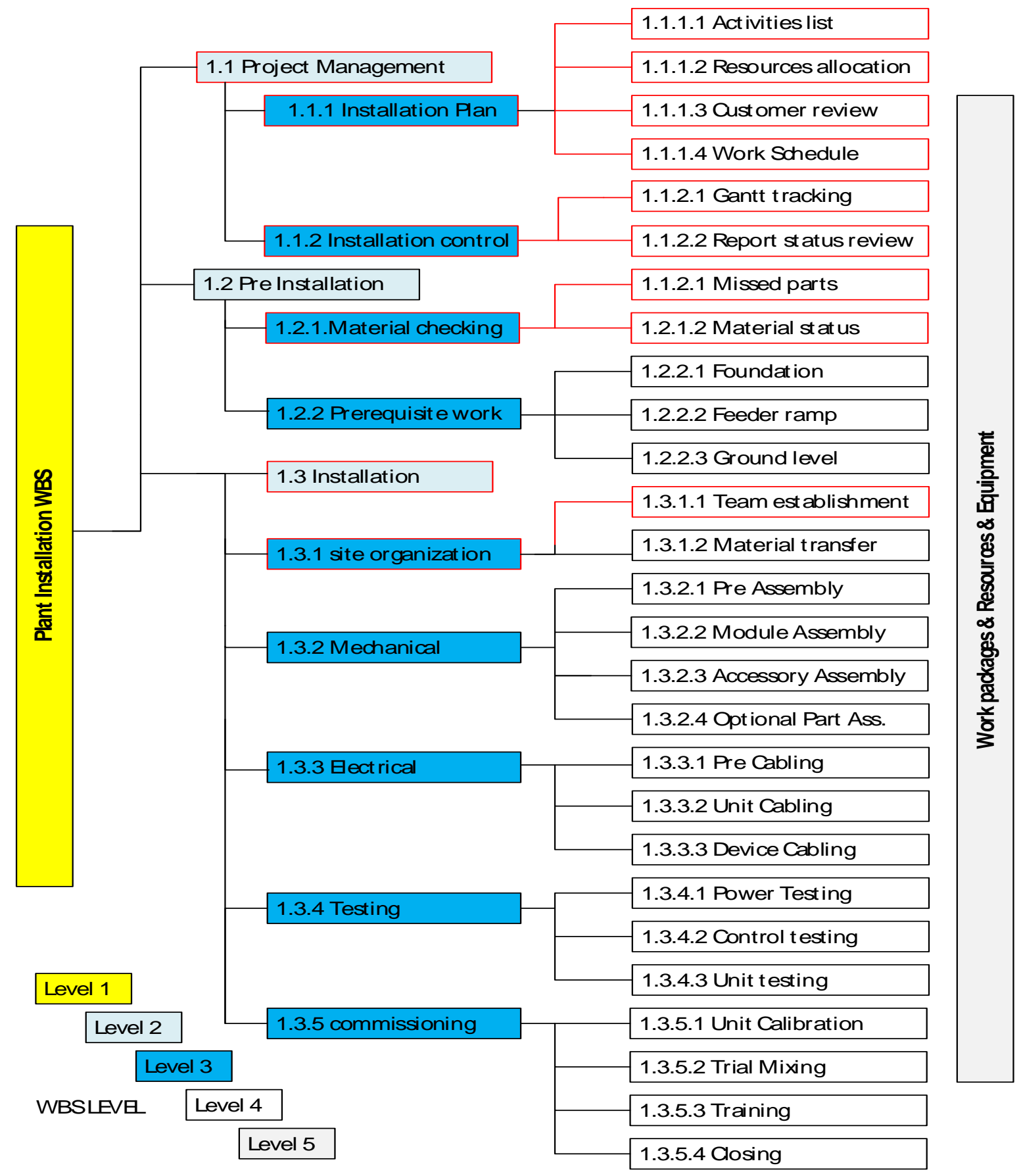

Figure 3. Proposed Installation WBS [15]

The project management as a WBS element, according to the problem analysis, company reports, and the experts' viewpoints, in the current WBS doesn't include or it did not efficiently work. Therefore, the first component of the second level of the proposed WBS, as shown in figure 3 , is the project management, where the first level is the plant itself with three subcomponents at level 2. However. the offered WBS template highlights the importance of the project manager to improve the planning and control over the whole installation work package. 
The project management includes two branches, installation plan, and installation control. The installation plan covers the worklist classification, resources allocation, customer review, and the last key is creating the schedule based on the customer capability and availability, these are the initial points on the road of proper installation, in such way, all participants will be involved. Meanwhile, the installation control establishes a framework to improve the control of the workflow by applying a standard template to trace the work schedule and job site status, therefore, the response to any possible risk becomes faster than the previous situation.

At the pre-installation level, the material and site conditions will be managed separately from the work activities, which will increase control and risk assessment efficiency. Meanwhile, the installation level redesigned to be more fixable and valid for several plant size, that will simplify the estimation for the work volume. A new branch was added to cover the team establishment, which will ensure the quality of the installation team.

According to the proposed WBS, the work packages identification should be determined by the project manager, for each plant model, and attached with each work package the required activity list to accomplish the $100 \%$ of the work package. However, it is not easy to list it hereunder, given that the work packages of the plant installation are varying for each plant model and it's in connection with the special technical field. Further, the project manager should assign resources to perform each activity, as per the expert's point of view, the resources list includes the qualified labor, equipment, and installation tools

\section{Installation Control framework}

Based on the proposed WBS, the Control framework was developed to improve the implementation of the WBS, the framework improves the tracking of the schedule, as well as, enhances the risk assessment plan by detecting the installation risk once it occurs. Figure 4 shows the proposed WBS control frameworks. The procedure starts by sharing the information with the customers, to evaluate the customer availability and capability, for starting the installation as well as providing the required resources for installation WBS implementation. Therefore, this procedure will help in reducing the time and cost of solving any risks due to poor planning of resources or any conflict due to lack of resources. Once both parties agreed to the installation plan, the Project manager starts creating the installation schedule according to the assigned resources and confirm the starting point.

Later on, the installation team will implement the installation schedule by the supervision of the service engineer and the cooperation of the site engineer, given that he is acting as a team manager, but unfortunately, he doesn't have direct power over the installation team. Thus, the cooperation of the customer site engineer is necessary to control the installation WBS schedule. Schedule tracking is a continuous task, as long as, the installation is running. The tracking and reporting will be done by the service engineer and the site engineer to keep the work progress running smoothly, to determines risk and reports the work status to the project manager and the customer. All installation risk will be classified and evaluated by the service engineer to determine the source of each risk. Then the response strategy will be agreed, evaluated, and implemented based on the risk owners. The work 
status reports and the risk list will be analyzed later on by the project manager to be used in improving the upcoming installation plans.

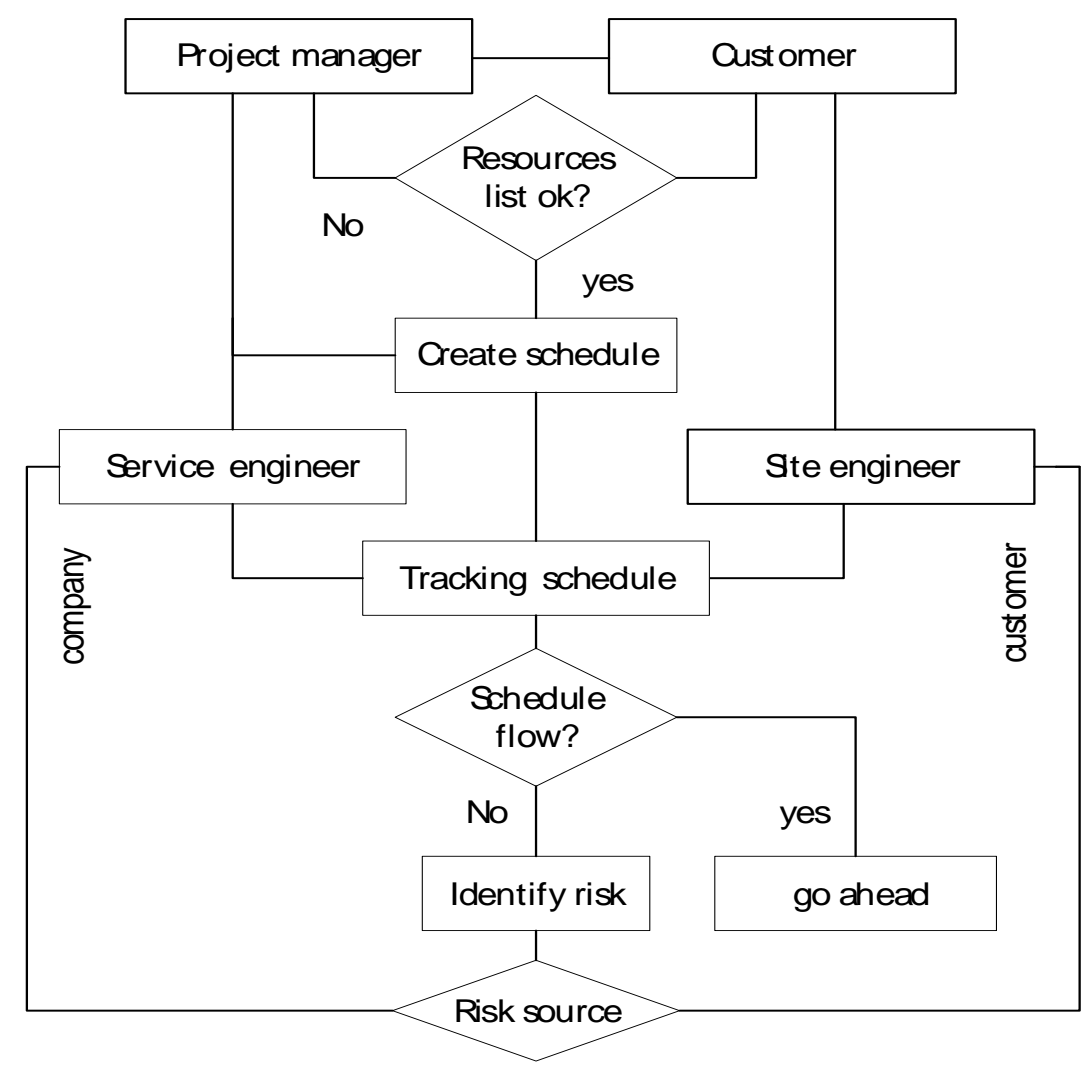

Figure 4. Proposed WBS Control Framework [15]

\section{Installation schedule}

The proposed installation schedule developed based on the proposed WBS. Which is limited to the assigned resources list, and the control framework. Table 7 shows the estimated time and cost required for installing the three examined model according to the proposed installation schedule.

\begin{tabular}{|l|c|c|c|}
\hline Plant model & $\begin{array}{c}\text { Estimated time } \\
\text { Day }\end{array}$ & $\begin{array}{c}\text { Estimated working } \\
8 \mathrm{H} / \mathrm{D}\end{array}$ & $\begin{array}{c}\text { Estimated } \\
\text { installation cost }\end{array}$ \\
\hline Model I & 65 & 600 & $€ 26,000$ \\
\hline Model II & 47 & 400 & $€ 18,800$ \\
\hline Model III & 25 & 240 & $€ 10,000$ \\
\hline
\end{tabular}

Table 7. Estimated time and cost based on proposed WBS [15]

By comparing the estimated time and cost of the proposed WBS with the estimation installation time and cost as shown in table 2, for model I, the reduction in time and cost will be about $13 \%$, while for model II the reduction is close to $6 \%$, as well as, in model III, the reduction is $16 \%$. the result is limited to the direct cost of the service engineer.

However, if the result is compared with the overall average installation time as shown in table 3 , the result will be clearer, given that the proposed WBS will help in solving the installation risk that results 
in increasing the time and cost. Table 8 clarifies the expected reduction in installation time based on the proposed WBS.

\begin{tabular}{|c|c|c|c|c|c|}
\hline \multirow{2}{*}{ Plant model } & \multicolumn{2}{|c|}{ Estimated installation time } & \multicolumn{2}{c|}{ Reduction } \\
\cline { 2 - 6 } & Average & overall & proposed & Average & overall \\
\hline Model I & 75 & 91 & 65 & $13 \%$ & $28 \%$ \\
\hline Model II & 50 & 64 & 47 & $6 \%$ & $26 \%$ \\
\hline Model III & 30 & 42 & 25 & $16 \%$ & $40 \%$ \\
\hline
\end{tabular}

Table 8. Reduction in installation time based on the proposed WBS [15]

Achieving the proposed result is required some advice and recommendation in implementing the installation WBS. The service engineer or the installation manager is the key person of the plant installation process and he is the last planner of plant installation plan. So, by following some lean techniques such as the last planner system (LPS), The LPS is focused on reducing the number of risks among the project throughout the use of collaborative and pull planning techniques [17]. The service engineer is the last planner, who is owned a huge experience and ideas of plant installation. The LPS technique allows him to contribute his ideas and experience during the WBS development It is necessary to improve his role in planning. In addition, providing him a sufficient training for using the project management tools such as; WBS and Gantt charts, risk management, and conflict management. to allow him to track the work schedule Furthermore, improving his leadership skills and proficiency level.

Risk reduction is an important factor in reducing installation time and cost. The waste elimination is another lean technique can be used during the installation, the waste is defined as "something adds no value ", [19]. in the plant installation, no value means extra time and cost as well as It's a huge source of risk. Therefore, the service engineer should talk care of all source of waste. One of the most used methods to minimize or eliminate the waste is the $5 \mathrm{~S}$ methodology which is a useful lean technique to convert unorganized workspace into more efficient and productive workplace. The $5 \mathrm{~S}$ is an abbreviation for sort, set in order, shine, standardize and sustain, [20] Also, it is recommended to be used by the service engineer to improve the workplace organization and the WBS implementation.

\section{Conclusion}

The WBS as a project scope identification tool offers a good opportunity to improve the project implementation. Increasing the collaborations among the project members easily can eliminate several sources of project risk. Also, the use of a good framework to control the project WBS flow leads to enhance the response of any risk could occur during the project implementation.

Theoretically, the result of the research shows that there is a possibility to improve the installation WBS, thus, the company may save a lot of efforts and cost, that were costing a lot of useless working hours. The next stage will be carried out by the case company to validate the proposed result by enhancing the current situation, given that according to the proposed schedule, the validation process requires minimum two months for the stationary plants -Model I and Model II - and one month for 
mobile plant-Model III. However, according to the review of the case company expert's viewpoint, the result is close to the real situation.

\section{Reference}

[1] S. Leni - L. Yusuf - S. Budi - Miralia R. (2017) Development of Risk-Based Standardized WBS for Cost Estimation of Apartment's Project. International Journal of Civil Engineering and Technology.

[2] Q. W. Fleming - J. M. Koppleman (1996) Earned value project management. Project Management Institute, Upper Darby, Pa.

[3] M. Fleishman (1998) Earned Value Performance Measurement: An Alternative Approach to Measuring Information Systems Project Progress. URI: https://hdl.handle.net/10539/24386

[4] J. Lewis (2007) Fundamentals of Project Management. Third edition. New York: American Management Association.

[5] Project Management Institute. (2013) A guide to project management body of knowledge PMBOK Guide - Fifth edition, Pennsylvania,

[6] G. T. Haugan (2002) Effective Work Breakdown Structure, Vienna: Management Concepts.

[7] L. A. Smith - J. Mills (1983) Reporting characteristics of automated project-management systems. International Journal of Project Management, 1, 155-159.

[8] V. S. Reddy - T. R. Devi (2012)Work Breakdown Structure of the Project. International Journal of Engineering Research and Applications.,

[9] G. Bachy - A-P. Hameri (1997) What to be implemented at the early stage of a large-scale project. International Journal of Project Management, 15, 211-218.

[10] Project Management Institute. (2006) Practice Standard for Work Breakdown Structures (WBS). Second edition (Reaffirmed). Newtown Square, PA: PMI.

[11] W. Hall (1993) Scope Management through a WBS. PM Network, 7(5).

[12] S. Globerson (1994) Impact of various work-breakdown structures on project conceptualization. International Journal of Project Management, 12, 165-171.

[13] G. R. Heerkens (2002) Project Management. New York, NY: McGraw-Hill Publishers.

[14] K. Colenso (2000) Creating the Work Breakdown Structure. Artemis Management Systems,

[15] Own source.

[16] Z. Sigmund - M. Radujković (2014) Risk breakdown structure for construction projects on existing buildings. Procedia-Social and Behavioral Sciences. http://dx.doi.org/10.1016/j.sbspro.2014.03.100.

[17] M. Russell - G. Howell - S. Hsiang - M. Liu (2012) Causes of time buffer in construction project task durations. Proc. 20th Ann. Conf. Int'l. Group for Lean Construction, San Diego, USA.

[18] B. V. Hancock (2015) Survey of Risk Assessment Practices, Enterprise Risk Management Initiative, North Carolina State University.

[19] S. Sarhan (2015) The concept of waste as understood in lean construction. Lean Construction Blog, http://leanconstructionblog.com/The-Concept. Retrieved on 01/05/18, at 15:45 pm.

[20] O. Omogbai - K. Salonitis (2017) The implementation of $5 S$ lean tool using system dynamics approach. Procedia CIRP, 60, 380-385. 